\title{
The Effect of Pschoeducation of Stress and Progressive Muscle Relaxation Practice Towards Decreasing Stress Level of Church Deacon Workers
}

\author{
Ricky Valentino Santoso ${ }^{1}$, Nilam Widyarini ${ }^{2}$ \\ Gunadarma University, Indonesia (Rickyvalentinosantosospsi@gmail.com) \\ Gunadarma University, Indonesia (nilam.wid@gmail.com)
}

\begin{abstract}
The church deacons as the social worker are more likely to have stress. It happens because their works are full with needs and emotions. Their stresses are coming from the congregation (members of church) who need help of the financial problems which is out of the capability of the church deacons. The purpose of this research is to decreasing the stress level of the church deacons. This research is using the non-random subject sampling as known as the saturated sample, which the intervention is given to 11 church deacons. The intervention is a psycho education for stress and progressive muscle relaxation and 7 sessions of progressive muscle relaxation practice. This is an experimental research with one group pre-test post-test design. Using the PSS-10 (Perceived Stress Scale-10) test for data sampling and Wilcoxon Signed Rank Test for data analysis. The intervention output shows there is a significant decreased stress level on church deacons $(Z=-2.952, a=.003)$.
\end{abstract}

Keywords: Stress, progressive muscle relaxation 


\section{Preliminary}

Church have a function named church calling (three duty of church) such as koinonia (fellowship), marturi (testimony) and deaconia (ministry). These three are related to one another because a whole church is the church that carries out its three vocations (Widyatmadja, 2009). Koinonia is a worship every Sabbath at church, marturia is the duty of the church to testify to others and deaconia is a ministry.

Diaconia literally means giving and it is a service carried out by the church that aimed at the needy which develops into social activities (Noodegraaf, 2004). The importance of the role of deacons in carrying out their vital functions is because they are assigned to give to those who are in need. In line with their important functions, deacon workers must be able to answer the needs of the congregation. The needs of the congregation that can be handled will be handled, but on the other hand, the needs that cannot be handled because it is beyond the deacon's capability and resources will become demands. This demand can produce stress on the work of deacons. This is in line with the opinion of Dahlui, Chinna \& Sundram (2006) which explains that stress is an imbalance between excessive demands and a person's ability to cope with it canleads to stress.

Deacon workers who is social workers, are vulnerable to stress because their works are full of demands and emotions. In line with Lloyd's opinion in Challis, Jacobs, Jasper, Manthorpe, Stevens, Netten \& Wilberforce (2014), neither social workers in social organizations can experience stress. It is because social work is a job that is full of demands, part of the source of stress comes from individuals who have professions who work in emotional situations, often with complex social situations and in unsupportive environments.

The stress that arise in the deacon's work appears as a response to the pressures given by the congregation as an environment where deacons work. In accordance with Patel's (2014) opinion, stress is emotional and physical pressure that arises as a result of an individual's response to what is happening around him. Stress is a multidimensional phenomenon that focuses on the dynamic relationship between individuals and their environment.

The stress that occurs in the diaconal worker comes from the congregation or externals causing negative emotions and physical pain. In accordance with Abadi, Kalkhoran \& Shahsavarani (2015) that stress can come from externally or originate from the environment or due to perceptions in a person that will produce anxiety and or emotions, negative feelings such as pain, sadness and so on, resulting in serious psychological disorders such as post-traumatic stress disorder.

Individuals have stress or perceive a problem as a threat or a dangerous thing whenever they do not have sufficient internal resources to overcome the obstacles in the form of stimuli, people or situations (Lynch, Kaplan \& Sherma 2012). Therefore, it can be concluded that the deacon worker interprets the demands of the congregation as a threat because the they do not have sufficient resources to complete each of the demands of the church. In this study, the researcher wanted to do stress level difference test on X church deacon workers before and after being given psychoeducation and progressive relaxation therapy training.

According to Jain (2011), managing stress can be done with pharmacological therapy, which includes the use of anxiety and anti-depressant drugs as well as nonpharmacological such as therapy with behaviour, cognitive and relaxation approaches. Therapy with muscle relaxation can calm the heart rate, lower blood pressure and lower 
stress hormones. Therefore, it can be concluded that muscle relaxation is a therapy that can be used to reduce stress levels in individuals.

Progressive muscle relaxation which can be used to reduce stress levels is also supported by the opinion of Dewi, Ilmi \& Rasni (2017) which in order to reduce stress levels in individuals can be used a variety of techniques where one of the stress management can reduce stress levels, namely progressive muscle relaxation which included in the physical strategy. In addition, progressive muscle relaxation does not only cope or reduce stress levels where Deckx, Hert, Knapen, Maurissen, Probst,Remans \& Vancampfort (2011) explain that progressive muscle relaxation techniques are considered a therapy for dealing with stress, anxiety and depression.

Progressive muscle relaxation is a method of relaxation to reduce tension, relax muscles regularly and sequentially until all parts of the body relax. This technique involves systematic tension and relaxation of the large muscles in the human body (Ibrahimoglu \& Kanan, 2017).

Progressive muscle relaxation therapy works by reducing the activity of the sympathetic nervous system when stimulated by a physiological response which ultimately lowers heart rate, respiratory rate and blood pressure and regulates the peripheral and central nervous system so that in the end it can reduce levels of stress, anxiety and depression (Lee et al, 2018). Furthermore, progressive muscle relaxation decreases the tension of the sympathetic nervous system and increases the parasympathetic nervous system so that the heart rate slows down, blood pressure decreases, the respiratory rate slows down, the metabolic rate slows down, the pupils enlarge to become peripheral dilates and increase the peripheral temperature so that blood flow to the muscles increase, decreased muscle stiffness, stress, fatigue and pain which make sleeps more comfortable. With all the positive effects it can provide more energy, deeper rest, more refresh and productive in daily activities (Ibrahimoglu \& Kanan, 2017).

Departing from the background, this research needs to be done considering that church workers have a large enough responsibility towards the congregation and the high level of stress can interfere their functions in life, therefore with this study it is hoped that deacon workers can provide better service, and not interfere their family life.

From the existing description, a research hypothesis can be made, which is a decreased in the level of stress in deacon workers after being given intervention in the form of psychoeducation about stress, progressive muscle relaxation and its practice.

\section{Research methods}

The subjects in this study were 11 deacons of church $X$ consisting of 3 men and 8 women with an age range of 31 to 50 years old, while the length of the subject's ministry in church $\mathrm{X}$ ranged from 5 to 7 years. The sample in this study were all deaconworkers in church $\mathrm{X}$ who are the subjects. The sampling technique was non-random sampling, also known as saturated samples.

This study used a field experiment method, namely quasi-experimental. The research design is a one-group pre-test post-test design or also known as before-after design. The independent variable of this study is psychoeducation about stress, stress coping and progressive muscle relaxation and its practice, while the dependent variable is the level of stress on deacon work.

The instrument used in this study was the PSS-10 (Perceived Stress Scale-10). Cohen, Kamark \& Mermelstein (1983) explained that the PSS-10 was designed to measure the extent of situations in one individual's life were assessed as stressful. This 
scale consists of 10 items that are compiled based on individual experiences and perceptions about what they feel in their life, such as feeling of unpredictability, feeling of uncontrolled and feeling of being overloaded. The items distribution for the dimension of unpredictable feelings represented by items number 1 and 6 (favourable) and items number 4 and 5 (unfavourable), while the dimension of uncontrolled feeling is represented by items number 2 and 6 (favourable) and item number 7 (unfavourable)

, for the last dimension, the stressed feeling dimension is represented by items number 3,8 and 9 (favourable). The PSS-10 test tool uses a scale from 0 to 5 while the consistency of internal reliability is .78 in the Harris Poll sample and .91 in the enation sample in 2006 and 2009 (Cohen \& Deverts, 2012).

Based on Bhat, Sameer \& Ganaraja (2011), there are three categories of the norms PSS-10 scale, (1) mild stress on a scale of 0-13, (2) moderate stress with scale of 14-26 and (3) severe stress on a scale 27-40.

The initial stage of this research (pre-implementation) is conducting interviews, observations and home visits to the congregation pastor of church $\mathrm{X}$, deacon workers and deacon workers families. The demographic data that the researchers obtained were the name, age and origin of the area where the deacon worked, while through the resultsof interviews, observations and home visits, the researcher got a picture of the stress, symptoms and consequences of stress experienced by the deacon worker. After that, the researcher conducted a pre-test using the Perceived Stress Scale (PSS-10) research instrument to 11 deacon workers at church $\mathrm{X}$ to measure the stress level of deacon workers before being given intervention or treatment.

The next stage, the researcher began to provide interventions in the form of giving psychoeducation by means of seminars or presentations on stress and progressive muscle relaxation plus progressive muscle relaxation practices which were packaged into 7 sessions. In practicing progressive muscle relaxation, the researcher used a guidebook and instructions for progressive relaxation exercises by Soewondo (2014). The sessions divided to 1 session in the first week, 2 sessions in the second, third and fourth weeks. In the final stage, the researcher conducted a post-test by givingthe research instrument the Perceived Stress Scale (PSS-10) to measure the level of stress after the deacon worker was given intervention. The data analysis technique used in this study was the Wilcoxon Signed Rank Test using Statistical Product and Service Solution (SPSS) 23.0 application for Windows. 
3. Results and Discussion

Table 1. Comparation of PSS-10 Pre-test and Post-test Score

\begin{tabular}{llllll}
\hline No. & Iinitials & $\begin{array}{l}\text { Pre-Test } \\
\text { Score } \\
\text { PSS-10 }\end{array}$ & Category & $\begin{array}{l}\text { Post-Test } \\
\text { Score } \\
\text { PSS-10 }\end{array}$ & Category \\
1. & N & 20 & Moderate & 8 & Mild \\
2. & A & 23 & Moderate & 11 & Mild \\
3. & T & 18 & Moderate & 13 & Mild \\
4. & L & 25 & Moderate & 13 & Mild \\
5. & J & 25 & Moderate & 11 & Mild \\
6. & SH & 24 & Moderate & 12 & Mild \\
7. & R & 21 & Moderate & 13 & Mild \\
8. & S & 27 & Severe & 12 & Mild \\
9. & MM & 28 & Severe & 15 & Moderate \\
10. & Y & 26 & Moderate & 11 & Mild \\
11. & D & 24 & Moderate & 16 & Moderate \\
\hline
\end{tabular}

Based on the results of the pre-test and post-test on the $\mathrm{X}$ church deacon, there is a change in the stress level score between before and after being given intervention or treatment. The post-test result is a decrease in the level of stress felt by all deacon workers over the past month (after 7 sessions), from September $5^{\text {th }}$ to October $7^{\text {th }} 2018$ which was measured using the Perceived Stress Scale (PSS-10) test kit after beinggiven an intervention in the form of psychoeducation regarding stress, progressive relaxation and progressive relaxation practices.

From table 1.1, there are 9 deacon workers with moderate stress levels and 2 deacon workers with severe stress levels at the time of the pre-test. Then in the post- test, it was found that there was a decrease in the stress level of deacon workers, there were 9 deacon workers with a mild stress level and 2 deacon workers with a moderate stress level where one deacon worker (D) experienced a decrease in the stress level score but remained in the moderate stress category.

Table 2. Statistic Description

\begin{tabular}{llllll}
\hline \multicolumn{2}{l}{ Descriptive Statistics } & & & \\
& & & Std. & Minimu & Maximu \\
& $\mathrm{N}$ & Mean & Deviation & $\mathrm{m}$ & $\mathrm{m}$ \\
Pre-test & 11 & 23.7273 & 3.03615 & 18.00 & 28.00 \\
Post-test & 11 & 12.2727 & 2.14900 & 8.00 & 16.00 \\
\hline
\end{tabular}

There is a decrease in the stress level score of all deacon workers. It shows from the pre-test, the average score of the stress level of deacon workers was 23.7, which means that the stress level was moderate. Then after being given the interventionor posttest, the average score for the stress level of deacons is 12.27 , which means that the level of light stress. 
Table 3. Wilcoxon Ranking Table

\begin{tabular}{lllll}
\hline Ranks & & N & \multicolumn{2}{l}{ Mean Rank Sum of Ranks } \\
Post-test - Pre-test & $\begin{array}{l}\text { Negative } \\
\text { Ranks }\end{array}$ & $11^{\mathrm{a}}$ & 6.00 & 66.00 \\
& $\begin{array}{l}\text { Positive Ranks } \\
\text { Ties }\end{array}$ & $0^{\mathrm{b}}$ & .00 & .00 \\
& $0^{\mathrm{c}}$ & & \\
& Total & 11 & & \\
$\begin{array}{l}\text { a. Post-test }<\text { Pre-test } \\
\text { b. Post-test }>\text { Pre-test } \\
\text { c. Post-test }=\text { Pre-test }\end{array}$ & & & \\
\hline
\end{tabular}

From table 3, it shows that the negative ranks or the negative differencebetween the results of the progressive muscle relaxation intervention before and after the intervention is $\mathrm{N}=11$ or eleven deacon workers experienced a decrease in the stresslevel score. From the mean rank, it is found that the average reduction in the stress levelscore of pre-test and post-test is 6.00 and the value of ties is 0 , it means that there is not the same value between the pre-test and post-test.

\section{Table 4. Wilcoxon Pre-test and Post-test Statistic Test}

\begin{tabular}{ll}
\hline Test Statistics & Post-test \\
& - \\
& Pre-test \\
& $-2.952^{\mathrm{b}}$ \\
$\mathrm{Z}$ & .003 \\
Asymp. Sig. (2-tailed) & \multicolumn{2}{l}{ a. Wilcoxon Signed Ranks Test } \\
\multicolumn{2}{l}{ b. Based on positive ranks. } \\
\hline
\end{tabular}

To see whether there is a significant change in the stress level of the pre-test and post-test that has been carried out, the Wilcoxon Signed Rank Test is used. As for the results of the Wilcoxon Signed Rank Test, it can be concluded that there is a meaningful and significant difference between the stress level in the pre-test and post- test which $\mathrm{Z}$ $(\mathrm{Z}=-2.952, \mathrm{p}=.003,<.05)$.

The decreasing stress levels in deacon workers after the intervention was due to two things. First is the psychoeducation that been given, which are the introduction and explanation of stress, stress coping and progressive muscle relaxation so the deacon worker can understand the stress they experienced, how stress coping is used and recognize progressive muscle relaxation. An understanding of stress, stress coping and progressive muscle relaxation helps the deacon worker to identify the causes of stress, what kind of stress coping has been used and the aftermath of stress so that progressive muscle relaxation is needed to reduce the stress level of deacon workers.

The second thing, after understanding progressive muscle relaxation is practicing progressive muscle relaxation. The practice is carried out for 5 sessions, dhat 
could reduce the deacon worker's tension and reduce negative emotions such as anger until a decrease stress levels is obtained at the end of post-test.

The results of this study are supported by a research by Patel (2014) which also shows changes in stress levels in nurses in the city of Vadodara before and after being given progressive muscle relaxation. Comparison between pre-test and post-test stress scores showed a significant reduction in the level of significant nurses after being given progressive muscle relaxation therapy. As well as research by Chandra \& Rajitha (2018) which resulted in a significant difference between pre-test and post-test on the stress level of nursing staff at WHO after being given relaxation with progressive muscle relaxation techniques.

The reduction stress level of deacons using the progressive muscle relaxation method is caused by a decrease in the tension of the sympathetic nervous system and an increase in the parasympathetic nervous system which make the heart rate slows down, blood pressure decreases, the respiratory and the metabolic rate slow down, the pupils enlarge into peripheral dilations and increase the peripheral temperature. These cause the blood more flowing to large muscles, decreased muscle stiffness, stress, fatigue and pain as could make sleep more comfortable. With all the positive effects, it can provide more energy, deeper rest, be fresher and more productive in daily activities (Ibrahimoglu \& Kanan, 2017).

\section{Conclusions and Recommendation}

\section{a. Conlusions}

Based on the result of hypothesis testing using the Wilcoxon Signed Rank Test technique, the value of $Z=-2.952$ was obtained with an Asymp.Sig of .003 which means it is smaller than the significance value of $\alpha=.05$. This means that the hypothesisis accepted, namely a decrease in stress level scores after being given intevention in the form of psycoeducation on stress, progressive muscle relaxation and progressive muscle relaxation practices. It was concluded that the intervention givven could be usedto help reduce stress levels in deacon workers.

\section{b. Recommendations}

Based on the result of this study, suggestions that can be considered, namely, for researchers who wish to carry out similar research, can take a sufficient number of subjects so that a control group can be formed so that can better describe the differences between the groups that were given intervention and not given the intervention. Second, taking subjects wih other backgounds or other situations so that can be seen the intervention in this study can have a positive and significant impact on subjects with other occupations. It's hoped that deacons of church X will continue to use progressive muscle relaxation which has been proven to reduce stress levels and for pastors can create a better social climate. 


\section{References}

Abadi, E. A M., Kalkhoran, M. H., \& Shahsavarni, A. M. (2015). Stress : Favts and theories though literature review. International of Medical Reviews, 2 (2), 230 241.

Bandopadhyay,A. K., Chaudhuri, A., \& Ray, M. (2014).Effect of progressive muscle relaxation on in female health care professionals. Journals of Medical and Health Sciences Research,4(5), 791 - 795.

Bhat, R. M., Sameer, M. K., \& Ganaraja, B. (2011). Eustress in Education: Analysis of the Perceived Stress Score (PSS) and Blood Pressure (BP) duringExaminations in Medical Students. J. Clinicaland Diagnostic Research, 5(7). 331 - 1335.

Challis, D., Jacobs, S., Jasper, R., Manthorpe, J., Stevens, M., Netten, A., \& Wilberforce, M.(2014). Revisiting the causes of stress in social work : sources of job demands, control and support in personalised adult social work. British Journal of Social Work, 44 (4), 812 - 830.

Chandra, A. S., \& Rajitha, S. R. (2018). Effectiveness of progressive muccle relaxation techinique on stress among staff nurses. International Journal of Multidisciplinary Research and Development, 5 (9), 58 - 62.

Cohen, S., Kamarck, T., \& Mermelstein, R. (1983). A global measures of prceived stress. Journal of Health and Social Behavior, 24 (4), 385-396.

Cohen, S., \& Janicki, D. (2012). Who's stressed? Distributions of psychological stress in the United States in probability samples from 1983, 2006, and 2009. Journal of Applied Social Paychology, 42(6), 1320 - 1334.

Dahlui, M., Chinna, K., \& Sundram, B. M. (2016). Effectiveness of progressive muscle relaxation therapys a worksite health promotion program in the automobile assembly line. Industrial Health, 54 (3), 201 - 214.

Deckx, S., Hert, M. D., Knapen, J., Maurissen, K., Probst, M., Remans, S., \& Vancampfort, D. (2011). Effects of progressive muscle relaxation on state anxiety and subjective well-being in people with schizophrenia: a randomized controlled trial. Clinical Rehabilitation, 25 (6), 567 - 575.

Dewi, E. I., Ilmi, Z., \& Rasni, H. (2017). Pengaruh relaksasi otot progresif terhadap tingkat stres narapidana wanita di lapas kelas IIA Jember. E-Jurnal Pustaka Kesehatan, 5 (3), 497 - 504.

Ibrahimoglu, O., \& Kanan, N. (2017). The effect of progressive muscle relaxation exercises after endotracheal extubation on vital signs and anxiety level in open heart surgery patients. Turk J Intense Care, 15, 98 - 106.

Jain, R. (2011). Pengobatan alternatif untuk mengatasi tekanan darah tinggi. Jakarta : Gramedia Pustaka.

Lee, K. S., Park, E. S., \& Yim, H. W. (2018). Progressive muscle relaxation theraphy to relieve dental anxiety: a randomiced controlled trial. European Journal of Oral Sciences, 127, 45 - 51.

Lynch, J. W., Kaplan, G. A., Shema, M. S. (2012). Cumulative impact of sustained economic hardship on physical, cognitive, psychological and social functioning. New England Journal of Medicine, 337 (26), 1889 - 1895.

Noodegraaf, A. (2004). Diakonia gereja : teologi dalam perspektf reformasi. Jakarta : Gunung Mulya.

Patel, P. (2014). A study to assess the effectiveness of progressive muscle relaxation therapy among staff nurses working in selected hospitals at Vadodara city. IOSR Journal of Nursing and Health Science, 3 (3), 34 - 59.

Soewondo, S. (2014). Panduan dan instruksi latihan relaksasi progresifww wak $_{\text {a }}$ arta LPSP3UI. 